\title{
An Investigation on the Relationship between Facial Emotional Recognition and Tendency to Commit Crime; Moderating the Effects of Socio-Economic Well-Being
}

By Nweke Ijeoma Blessing, Okoli Paul Chibuike, Ofojebe Chukwuma Philip, Ugboma Cajetan Ikechukwu, Akpoke Victor Okorieh, Ogundu Amara Grace \& Edoka Anthony Chukwunonye

Abstract- The growth of crime rates are on the increase all over the world and Nigeria is not an exception. Crime the intentional illegal action committed by any person for which such a person can punish by law does not have a definite cause but rather combination of causes which may include: economic situation, social environment, personality traits, and family structures. This study investigates if socioeconomic wellbeing has a mediating effect on relationship between facial emotional recognition and the tendency to commit crime among hospital workers in Imo state. A total of 150 (75 males and 75 females) workers, were randomly selected to participate in this study. Three instruments were used in this study which includes: Criminal Behaviour Rating Scale (CBRS) developed by Animasahun (2011), Socio-economic wellbeing scale developed by Obi-Nwosu (2018) and Facial emotion scale developed by Paul Ekman.

Keywords: facial emotional recognition, tendency to commit crime; socio-economic well-being.

GJHSS-H Classification: FOR Code: 170199

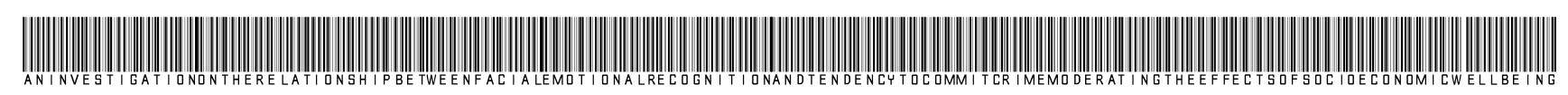

Strictly as per the compliance and regulations of:

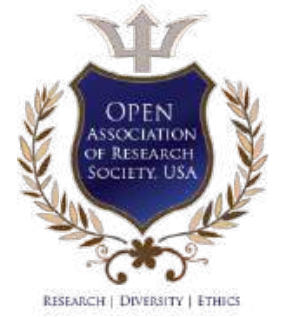

(C) 2020. Nweke Ijeoma Blessing, Okoli Paul Chibuike, Ofojebe Chukwuma Philip, Ugboma Cajetan Ikechukwu, Akpoke Victor Okorieh, Ogundu Amara Grace \& Edoka Antho ny Chukwunonye. This is a research/review paper, distributed under the terms of the Creative Commons Attribution-Noncommercial 3.0 Unported License http://creativecommons.org/licenses/by-nc/3.0/), permitting all non-commercial use, distribution, and reproduction in any medium, provided the original work is properly cited. 


\title{
An Investigation on the Relationship between Facial Emotional Recognition and Tendency to Commit Crime; Moderating the Effects of Socio-Economic Well-Being
}

\author{
Nweke Ijeoma Blessing ${ }^{\alpha}$, Okoli Paul Chibuike ${ }^{\sigma}$, Ofojebe Chukwuma Philip ${ }^{\circ}$, \\ Ugboma Cajetan Ikechukwu ${ }^{\omega}$, Akpoke Victor Okorieh", Ogundu Amara Grace \\ \& Edoka Anthony Chukwunonye ${ }^{x}$
}

Abstract- The growth of crime rates are on the increase all over the world and Nigeria is not an exception. Crime the intentional illegal action committed by any person for which such a person can punish by law does not have a definite cause but rather combination of causes which may include: economic situation, social environment, personality traits, and family structures. This study investigates if socioeconomic wellbeing has a mediating effect on relationship between facial emotional recognition and the tendency to commit crime among hospital workers in Imo state. A total of 150 (75 males and 75 females) workers, were randomly selected to participate in this study. Three instruments were used in this study which includes: Criminal Behaviour Rating Scale (CBRS) developed by Animasahun (2011), Socio-economic wellbeing scale developed by Obi-Nwosu (2018) and Facial emotion scale developed by Paul Ekman. The willing participants after signing the consent form were provided with copies of the questionnaires which were distributed and directives of how to fill them was given by the researcher. The researcher explained the content of the questionnaire and this helped the participants to easily fill the questionnaires independently. As participants turned in their questionnaires, the researcher administered the facial emotion recognition test to them individually repelling and discouraging interference from participants who were waiting to be assessed. After collecting the data, the questionnaires were collated and the data collected analyzed The Pearson's correlation was used to analyze the data. The result of the findings reveals that there is no significant correlation between socioeconomic wellbeing and the relationship between facial emotional recognition and tendency to commit crime ( $p=0.056$ in female; 0.476 in male). However significant ( $p=0.002$ ) relationship existed between socioeconomic wellbeing and tendency to commit crime. The implication of this finding is that individuals with higher socioeconomic wellbeing have a higher propensity to be involved in criminal activities. One other decimal to factor in this study is that most (142) participants earn $\leq \$ 40$ per day.

Author a $\rho$ : Department of Psychology, Nnamdi Azikive University Awka-Nigeria.

Author б: Ph.D, Department of Internal Medicine ESUT College of Medicine, Enugu State University of Science and Technology, EnuguNigeria.e-mail: okolipd71@gmail.com

Author w: Department of Psychology, Faculty of Educational Sciences, Universita Pontificia, Salesiana, Rome-Italy.

Author $¥ \xi$ : Department of Psychology, Enugu State University of Science and Technology, Enugu.
Poor income therefore can be a cause of dissatisfaction and thus the tendency to commit crime. It is recommended that policy makers formulate and maintain laws that must insist that workers are to paid adequately and promptly, so as to reduce the tendency to commit crime among them. Psychological assessment on personality for screen candidates for employment and making necessary intervention before employing workers and those already in service for preventive and prophylactic reasons.

Keywords: facial emotional recognition, tendency to commit crime; socio-economic well-being.

\section{INTRODUCTION}

\section{a) Background to the Study}

rime is one of the major problems confronting humanity across the world. Nations have grappled to contain the rising incidence of homicide, armed robbery, kidnap, drug trafficking, human trafficking, illegal gun running and host of others. In modern criminal law, the term 'crime' does not have any simple and universally accepted definition, though statutory definitions have been provided for certain purposes (Farmer, 2008). One of the proposed definitions is that a crime is an act harmful not only to some individuals but also to a community, society or the state; such acts are forbidden and punishable by law (Martin, 2003). Another definition is that it is a straightforward sense is law-breaking, or more conditionally, violation of the criminal law as agreed within a given jurisdiction at a particular time, although criminal law is usually enduring once established (Webster and Kingston, 2014). Looking at its prevalence, United Nations Office on Drugs and Crime in 2011 estimated global homicides at 468,000 and more than a third (36\%) was estimated to have occurred in Africa, $31 \%$ in the Americas, $27 \%$ in Asia, $5 \%$ in Europe and $1 \%$ in the tropical Pacific region (UNODC, 2011). More so, crime in the local scene manifest in the convulsive upsurge of both violent and nonviolent crimes (Emeh, 2011). Incidents of armed robbery, assassination and ransom-driven kidnapping are now ravaging the polity and spreading a climate of fears and 
anxieties about public safety (Emeh, 2011). Other major crimes in Nigeria include rape, burglary, fraud, terrorism, cyber-crimes, bribery and corruption, money laundering, etc. (Oguntunde et al, 2018).

Considering the significance of the damage criminal activities cause to individuals, attempts have been made by scientist from different disciplines to find out which people are likely to become criminals and what drives certain individuals to commit crime in the first place (Moore, 2011). One of such disciplines in the fore front of studying crimes and criminals is Psychology. Many studies on criminal behaviour have identified antisocial behaviour as a viable predicator of the tendency to commit crime (Hayward and Sharp, 2005; Shinder and Cross, 2008). Other studies have gone further to report that antisocial population have major deficit in facial emotion recognition (Marsh, 2008). Because of the positive correlation between crime and antisocial behaviours, facial emotion recognition has been extensively studied. The communication of emotions is an important aspect of human social interaction and a necessary component in the development of social competence. In particular, our ability to understand the emotional states as well as the interpersonal intent of another person is crucial within social contact (Blairy, Herrera and Hess, 1999).

Emotions have been described as psychological events that influence our behaviour by making some activities more desirable, more likely to be rewarding, and other activities less desirable because they are associated with negative or unpleasant outcomes, and unlikely to be rewarding (Skuse, 2003; Dolan, 2002). Facial expressions constitute the most important stimuli within this process and it has long been hypothesised that they specifically evolved to provide signals for rapid nonverbal communication (Darwin, 1872, as cited in Ekman, 1998). By looking at a person's face, familiar or unfamiliar, the observer can interpret the facial expression in terms of its emotional context. This provides information about that person's emotional state and sets the tone for social interaction (Posamentier and Abdi, 2003). It has been demonstrated that people do not display facial expressions automatically, or with the same strength that they actually experience a particular emotion internally (Fridlund, 1991). Instead, emotional facial expressions are enhanced when people are in the company of others compared to when an individual is alone (Chovil, 1991; Fridlund, 1991). This supports the notion that facial expressions are communicatory signals between individuals, rather than simply reflecting a person's own emotional state. Further, it has been proposed that facial expressions of others function as unconditioned stimuli within instrumental learning processes for social behaviour (Blair, 2003). In particular, expressions of fear, sadness and happiness are viewed as reinforcements that modulate the probability that a particular behaviour will be performed or inhibited. It has been shown that happy expressions function as a positive reinforcement and increase the likelihood that behaviours that are causally related to the happy expression will be carried out (Matthews and Wells, 1999). The observation of a fear expression alone is sufficient for conditioning processes to occur (Mineka and Cook, 1993). Consequently, difficulties with emotion recognition and or processing are likely to cause interference with an individual's ability to interpret and understand the emotional state of another person. The inability to correctly identify the emotional expressions of another individual could interfere with the learning of socially appropriate responses to emotional states of others. The process underlying the understanding of another's emotional and cognitive point of view is called "empathy". This term originally refers to the tendency of observers to project themselves "into" another person (Blair, 2005; Blairy, et al., 1999). It has also been described as "an effective response more in keeping with someone else's situations than one's own" (Hoffman, 1987).

Socio-economic wellbeing considers both the economic status and quality of life for people. Economic well-being is defined as having present and future financial security. Present financial security includes the ability of individuals, families, and communities to consistently meet their basic needs (including food, housing, utilities, health care, transportation, education, child care, clothing, and paid taxes), and have control over their day-to-day finances. It also includes the ability to make economic choices and feel a sense of security, satisfaction, and personal fulfilment with one's personal finances and employment pursuits. Future financial security includes the ability to absorb financial shocks, meet financial goals, build financial assets, and maintain adequate income throughout the life-span. Economic well-being may be achieved by individuals, families, and communities through public policies that ensure the ability to build financial knowledge and skills, access to safe and affordable financial products and economic resources, and opportunities for generating income and asset-building. It occurs within a context of economic justice within which labour markets provide opportunities for secure full-employment with adequate compensation and benefits for all (CSWE, 2016).

Social wellbeing on the other hand, is an end state in which basic human needs are met and people are able to coexist peacefully in communities with opportunities for advancement. It is the extent to which individuals feel a sense of belonging and social inclusion. Human beings are social creatures who are mutually dependent, relying on others for their wellbeing, just as others rely on them. People have the need to love and be loved; to belong and be connected (Goleman, 2018). Social wellbeing is characterized by 
equal access to and delivery of basic needs services (water, food, shelter, and health services), the provision of primary and secondary education, the return or resettlement of those displaced by violent conflict, and the restoration of social fabric and community life.

\section{b) Statement of Problem}

According to UNDOC (2011) report, Nigeria has one the highest crime rates in the world. Another recent report from National Bureau of Statistics (2016) shows a constant increase in the frequency of crimes committed in the country; 47,646 in 2013, 49.825 in 2014 and 50,153 in 2015. Being that crime is a global problem, and one that have been studied extensively, especially from the angles socioeconomic and psychological determinants, reports have shown that poor socioeconomic statues and psychological conditions (such as psychopathic) are individual predicators of the tendency to commit crime.

However, there is paucity of literature on the mediation of socioeconomic wellbeing on facial emotional recognition as a predicator of the tendency to commit crime. This current study therefore, aims to fill this knowledge gap.

c) Research Questions

1. Can different facial emotions be recognised?

2. What is the relationship between facial emotional recognition and the tendency to commit crime?

3. Does socioeconomic wellbeing have a mediating effect on the relationship between facial emotional recognition and the tendency to commit crime?

\section{d) Purpose of the Study}

This study aims to determine if socioeconomic wellbeing have a mediating effect on relationship between facial emotional recognition and the tendency to commit crime.

The specific objectives of this study include;

1. To determine if facial emotional recognition is a predicator of the tendency to commit crime.

2. To determine if socioeconomic wellbeing has mediating effect on the relationship between facial emotional recognition and the tendency to commit crime.

3. To determine if there is a mediating effect of socioeconomic wellbeing on the tendency to commit crime.

\section{e) Operational Definitions of Key Variables}

1. Tendency to commit crime: This is the measure of the likely hood to commit unlawful acts as measured using Crime Behaviour Rating Scale (CBRS) developed by Animasahun (2011).

2. Facial emotional recognition: This is the recognition of a form of nonverbal communication done by one or more motions or positions of the muscles beneath the skin of the face (Freitas-Megalhaes, 2011). This is measured using the recognition of different facial pictures.

3. Socioeconomic Wellbeing: This variable is measured using Socio-economic Well-being Scale developed by Obi-Nwosu, (2018).

\section{Method}

\section{a) Participants}

The participants for this study were one hundred and fifty (150) hospital staff. They comprised of 75 (50\%) males and 75 (50\%) females drawn Federal Medical Centre, Owerri and General Hospital, Owerri, both in Imo state Nigeria. Participants included permanent, casual and voluntary workers engaged by these facilities. There was no restriction to age of participants, however, the age of participants were 20 years and above. Inclusion criteria is that participants must be employed.

\section{b) Instrument}

Three instruments were used in this study. They are; Criminal Behaviour Rating Scale (CBRS) devel oped by Animasahun (2011), Socio-economic wellbeing scale developed by Obi-Nwosu (2018) and Facial emotion scale developed by Paul Ekman.

\section{c) Criminal Behaviour Rating Scale (CBRS)}

The crime behavior rating scale which is the first scale in the Crime Behavior Factor Battery and was developed by Animashaun (2011). The scale was used to measure the tendency of participants to commit crime. It has 33 items constructed on 5- point Likert format. It has a norm of 63 whereby any score above the norm is an indication of high crime tendency. It has a Cronbach Alpha of 0.95 and a Guttman split half reliability of 0.82 .

\section{d) Socio-economic Wellbeing Scale}

This instrument was developed using interviewer rated multivariate assessment of socioeconomic well-being by Obi-Nwosu, Balageul and Nwafor (2018). It contains Items which are scored from 1-5. Possible least total score is 12 , while possible highest total score is 60 . The higher the score, the better well-being is assumed; however, scores 12 to 36 depict low general socio-economic well-being, while scores 37 and above depict high socio-economic well-being. i. The items represents outcome of item analysis in a Nigerian sample. ii. Each of the Variates (domains): economy, Education, Social Interaction, Health, and Local Transportation may be assessed independently if desired. In that case, the norm is calculated thus: $N=$ $n \times 3+1$. Where ' $N$ ' represents norm, ' $n$ ' is the number of items, 3 is the theoretical mean, and 1 is a constant that produces a shift away from the mean. Using the general score however gives a more confident assessment of socio-economic well-being. 
e) Facial Emotion Scale

Facial Emotion Scale was developed by Paul Ekman. In this study Facial Emotion Scale was employed by using pictures of 8 (eight) different facial emotions; both male and female facial emotions were represented for each emotion. The emotions included sadness, anger, fear, surprise, shame, disgust, happiness, and excitement. Participants were presented with these pictures and asked to identify the facial emotion expressed. They are scored right or wrong depending on their ability to rightly recognise the facial emotions or not.

\section{f) Procedure}

A total of 150 copies of the questionnaires were randomly distributed to the participants in Federal Medical Center, Owerri and General hospital, Owerri by the researcher. Prior to this, an informed consent form was given to the participants and confidentiality was maintained as well. Also, the researcher sorted out the permission to carry out the research in the hospitals and this was granted by the various heads of departments. The research participants were told that participation is not compulsory and that information provided will only be used for academic purposes. The researcher explained the content of the questionnaire and this helped the participants to easily fill the questionnaires independently. As participants turned in their questionnaires, the researcher administered the facial emotion recognition test to them individually repelling and discouraging interference from participants who were waiting to be assessed. After collecting the data, the questionnaires were collated and the data collected analysed using SPSS version 20.

g) Design/Statistics

This is a survey design and spearman's correlation adopted for data analysis.

\section{ili. Result}

Tab. 1: Means, Standard Deviations and Correlation Coefficients

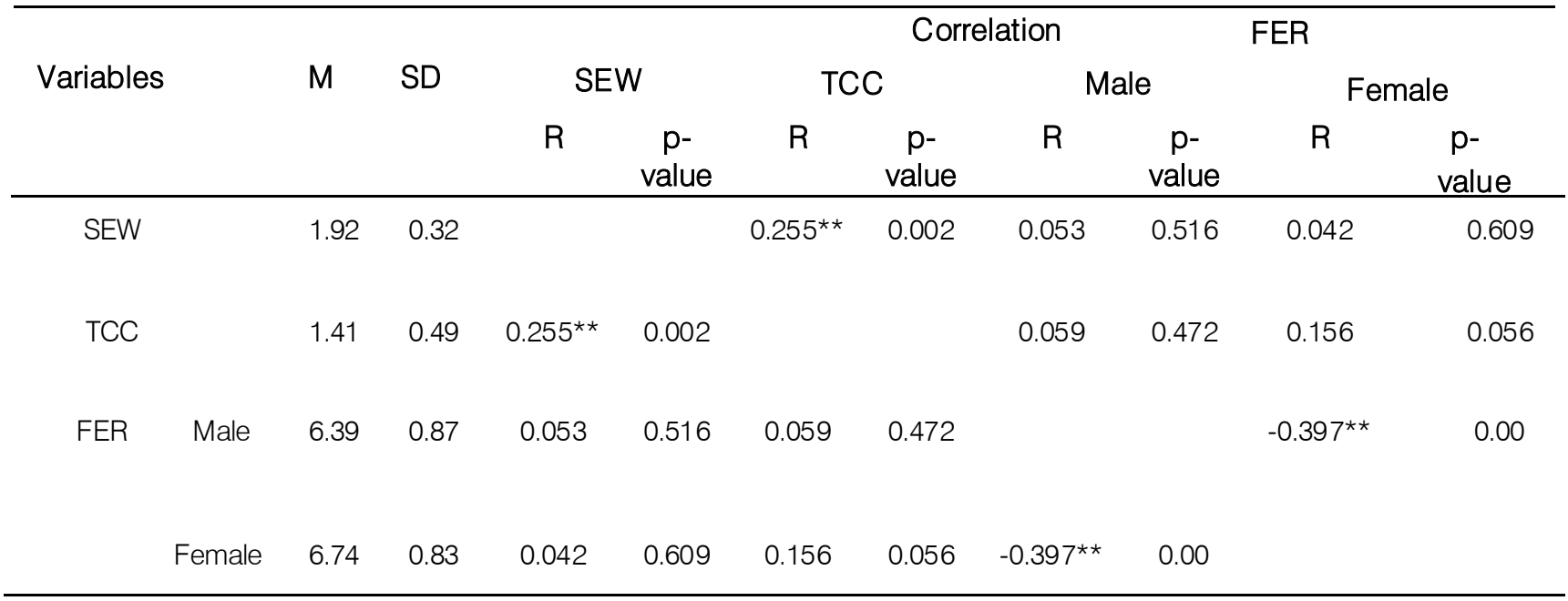

${ }^{* *} p<.01,{ }^{*} p<.05$

Note: $* *$ indicate a significant level at $p<.01, *$ ind icates a significant level at $p<.05$.

SEW $=$ Socioeconomic Wellbeing, TCC $=$ Tendency to commit crime, FER = Facial emotion recognition.

The inspection of the table above shows that there is a significant $(p=0.002)$ weak positive correlation socioeconomic wellbeing and tendency to commit crime. It also shows a significant $(p=0.00)$ negative correlation between the ability to recognise male facial emotions to recognizing female facial emotions. This chapter contains the presentation of data collected in the course of this study and the result of its statistical analysis which are presented in tables.

Tab. 2: Correlation of socioeconomic wellbeing and the relationship between facial emotion recognition and tendency to commit crime

\begin{tabular}{cccc}
\hline Relationship between FER and TCC & R & S.E & p-value \\
\hline Female & 0.156 & 0.079 & 0.056 \\
Male & -0.059 & 0.084 & 0.472 \\
\hline
\end{tabular}

$F E R=$ Facial emotion recognition

TCC $=$ Tendency to commit crime

$R=$ coefficient of correlation

$S . E=$ Standard error 
There is no significant correlation between socioeconomic wellbeing and the relationship between facial emotion recognition and tendency to commit crime.

\section{a) Summary of the findings}

1. There is no significant relationship between facial emotion recognition and tendency to commit crime.

2. There is a significant weak positive relationship between socioeconomic wellbeing and the tendency to commit crime.

3. There is a significant negative relationship between recognition of male facial emotions and recognition of female facial emotions.

4. There is no significant relationship between socioeconomic wellbeing and the relationship between facial emotion recognition and tendency to commit crime.

\section{Discussion}

This study assessed the modulating effect of socioeconomic wellbeing on the relationship between facial emotion recognition and tendency to commit crime is workers in Federal Medical Centre Owerri and General Hospital Owerri, both in Imo state. In the process of ascertaining the objectives of this study, three hypotheses were postulated and tested as well. The first hypothesis which stated that, 'Inability to recognise facial emotions will correlate positively and significantly to tendency to commit crime', was rejected. This indicates that the negative correlation between facial emotion recognition and tendency to commit crime in psychopaths could be strictly as a result of their condition. This study however, made an intriguing finding; there was a negative correlation between recognition of female facial emotions and male facial emotions. Existing literatures focus on the difference in the ability of male against female, to recognise different facial emotions. Popular among existing literature is the observation that female have a higher ability to recognise facial emotions than males (McClure, 2000; Boyatzis, Chazan, Ting, 1993). One of the explanations might lay in developmental psychology; children recognize emotions which they are also able to perceive and express themselves (Izard et al; 1995), starting from happiness, sadness and anger, and incorporating more complex ones in later development. Being more sensitive to other people's emotions could be gender specific and connected with being more susceptible to contagion by emotions of others, like it was stressed in the Dimberg and Lundqvist (1990) study.

The female accuracy might partially be connected to the gender difference of visual perception and the constant reinforcement loop consisting of recognition, perception and production of expression combined with a tendency to show emotions more frequently, what was proved especially for smiling (Briton \& Hall, 1995; Chapell, 1997). Also, it was found that women were more facially expressive than man on various emotional stimuli (Kring \& Gordon 1998; Gross and Levenson, 1993)and had significantly thicker zygomaticus major muscle (McAlister, Harkness and Nicoll, 1998), which is an explanation for better recognition of most of emotions expressed on a female face, although as we used only one male and one female actor this result could also be due to a better expression of the female actor. There was also a developmental difference in recognition of emotional expressions on female and male faces, the older participants being more successful, probably due to some cognitive processes accessible to training during development. It was previously established that high school students are more successful at facial expression recognition than elementary school students (Gaspar et al; 2011) and our results show that university students are also more successful than elementary school students. Another finding of the present study is there is no significant modulating effect of socioeconomic wellbeing on the relationship between facial emotion recognition and the tendency to commit crime.

The second hypothesis which stated that, 'socioeconomic wellbeing will correlate positively and significantly to the relationship between facial emotional recognition and the tendency to commit crime' was also rejected. There is however dearth of literature in this area of study and thus the findings of this study is totally a new knowledge. In this present study however a positive correlation was found between socioeconomic wellbeing and tendency to commit crime. Looking at other studies such as Ellis, Beaver and Wright (2009), socioeconomic wellbeing (measured using the three variables income (or wealth), occupational level, and years of education) correlates negatively with tendency to commit crime. This finding contradicts the findings of the current study where there is a positive relationship between socioeconomic wellbeing and the tendency to commit crime. There is however an agreement between the findings of this study and the study done by Baum, Garofalo and Yali (1999) where it was reported that low socioeconomic status is thought to be positively correlated with higher levels of stress, and therefore the mental and psychological ill-effects of stress. These higher stress levels would probably be correlated positively with the propensity to commit a crime. Some other studies, however, reported somewhat inconsistent evidence that indicates a positive relationship between low income levels, the percentage of population under the poverty line, low education levels, and high income inequality in an area with more crime in said area (Ellis, Beaver and Wright, 2009). A 2013 study from Sweden argued that there was little effect of neighbourhood deprivation on the tendency to commit crime per se and 
rather that the higher tendency to commit crime were due to observed and unobserved family and individual level factors, indicating that high-risk individuals were being selected into socioeconomically deprived areas (Sariaslan et al; 2013). In a study conducted in Nigeria, findings showed that determinants of economic wellbeing has positive correlation with tendency to commit crime while determinants of social wellbeing has negative correlation with tendency to commit crime (Omotor, 2010)

\section{a) Implication of Study}

The implication of this study is discussed in line with the findings of the study.

This study found a positive relationship between socioeconomic wellbeing and tendency to commit crime. This implies that individuals with higher socioeconomic wellbeing have a higher propensity to be involved in criminal activities. One other decimal to factor in this study is that most (142) participants earke $\$ 40$ per day. Poor income therefore can be a cause of dissatisfaction and thus the tendency to commit crime. This should therefore be an indication to policy makers to pay workers adequately, so as to reduce the tendency to commit crime among them.

\section{b) Limitation of the study}

The findings of this study are poised with some limitation that can never be overlooked in the course of future research.

Due to the small sample size used in this study, there should be caution in the generalization of the findings of this study. Thus, salient characteristics of a larger sample might have a profound effect on the criterion variable.

Also, most of the participants in this study are poor income earners, thus, a motivation can quickly be identified for their positive tendency to commit crime. It is therefore imperative that study on a sample population incorporating more individuals who are high income earners be considered.

More so, some individuals might not have answered some questions honestly, and as such, making a generalised assertion with the outcome of this study might be erroneous.

\section{c) Suggestion for Future Studies}

This study suggested some new directions for further research.

Researchers should re-conduct the present study in a different geopolitical zone using large sample size in order to ascertain the ecological validity of the study.

There should also be a study exclusively for high income earners and individuals who are satisfied with their jobs to compare the outcome with the outcome of this study in terms of the relationship between socioeconomic wellbeing and tendency to commit crime.

Finally, studies should be directed towards gender based disparity in recognition various facial emotions in either male or female.

\section{d) Conclusion}

This study investigated the modulating effect of socioeconomic wellbeing on the relationship between facial emotion recognition and tendency to commit crime among workers in Federal Medical Centre Owerri and General Hospital Owerri. Two hypotheses of this study were tested in line with the research question this study set to answer. From the findings, the first hypothesis was rejected showing that facial emotion recognition did not correlate positively and significantly with tendency to commit crime. The second hypothesis was also rejected since there was no modulating effect of socioeconomic wellbeing to the relationship between facial emotion recognition and tendency to commit crime.

However, this study made two findings;

1. A positive and significant correlation existed between socioeconomic wellbeing and tendency to commit crime.

2. A negative and significant correlation existed between recognition of male facial emotions and female facial emotions.

Conflict of interests

The authors declare that they have no financial or personal relationship(s) that may have inappropriately affected their report of the findings of this research.

\section{References Références Referencias}

1. Animasahun, R.A. (2011). The Menace of Examination Malpractices, Poor Academic Performance and Academic Failure Among Secondary School Students: Focus on Remediation. Paper Presented at a Workshop Organised by the Polytechnic Ibadan, Ibadan.

2. Baum, A., Garofalo, JP, \& Yali, AM (1999). Socioeconomic status and chronic stress. Does stress account for SES effects on health? Ann N Y Acad Sci.1999;896:131-144.doi:10.1111/j.17496632.1999.tb0811.x

3. Blair $J$ (2005). Responding to the emotions of others: Dissociating forms of empathy through the study of typical and psychiatric populations. Consciousness and Cognition. Volume 14, Issue 4, Pages 698-718.

4. Blair, R. (2003). Neurobiological basis of psychopathy. British Journal of Psychiatry, 182(1), 5-7.

5. Blairy, S, Herrera, P, \& Hess, U (1999). Memory and the judgement of emotional facial expressions. Journal of nonverbal Behaviouir, 23 (1), 5-41. 
6. Boyatzis CJ, Chazan E, Ting CZ. Preschool children's decoding of facial emotions. J Genet Psychol 1993; 154: 375-82.

7. Briton NJ, Hall JA. Gender-based expectancies and observer judgments of smiling Journal of Nonverbal Behavior 1995; 19: 49-65.

8. Chapell MS. (1997) Frequency of public smiling across the life span. Percept Mot Skills; 85: 1326.

9. Chovil, N. (1991). Social determinants of facial displays. Journal of Nonverbal Behavior, 15 141-154.

10. Council on Social Work Education (CSWE, 2016). Advancing collaborative practice through social work Education (Economic well-being in social works: New Curricular Resources for faculty). Atlanta, GA. https//www.tandfonline.com

11. Darwin, (1872), as cited in Ekman, P. (1998), Universality of emotional expression? A personal history of the dispute. In Ekman $\mathrm{P}$ (Ed.), The expression the emotions in man and animal (Ed., pp.363-393). New York: Oxford University Press.

12. Dimberg U, Lundquist LO. (1990) Gender differences in facial reactions to facial expressions. Biol Psychol ; 30: 151-9.

13. Dolan R. J (2002) Emotion, cognition, and behavior. Science; 298(5596): 1191-4.

14. Ekman, P. (1998), Universality of emotional expression? A personal history of the dispute. In Ekman P (Ed.), The expression the emotions in man and animal (Ed., pp.363-393). New York: Oxford University Press.

15. Ellis, Lee; Beaver, Kevin M.; Wright, John (2009). Handbook of Crime Correlates. Academic Press. ISBN 9780123736123.

16. Emeh, J. U. (2011). Education versus infectious diseases (ID) and the environment. A paper presented on the 14thof May, 2011 at stakeholders meeting organized by Centre of Excellence, World Bank Project 4, in University of Calabar, Calabar, Nigeria.

17. Farmer, L. (2008) "Crime, definitions of", in Cane and Conoghan (editors), The New Oxford Companion to Law, Oxford University Press, (ISBN 978-0-19-929054-3), p. 263.

18. Freitas A \& Megalhaes $J$ (2011). A review and appraisal of the DNA damage theory of ageing. Mutat Res. 728(1-2): 12-22.

19. Fridlund, A. J. (1991). Sociality of solitary smiling: Potentiation by an implicit audience. Journal of Personality and Social Psychology, 60 (2) , 229-240.

20. Gaspar T, Labor M, Juric I, Dumancic D, llakovac V, Heffer M. (2011) Comparison of emotion recognition from facial expression and music. Coll Antropol; 35 Suppl 1:163-7.

21. Goleman, D. (2018). It's Really Matter: Review of the book, Emotional Intelligence: Why it can matter more than IQ. Research Journal of Humanities and Social Sciences 9(3), 639-644.

22. Gross JJ, Levenson RW. (1993) Emotional suppression: physiology, self-report, and expressive behavior. J Pers Soc Psycho; 64: 970-86.

23. Hayward, R. and Sharp, C. (2005) Young people and anti-social behaviour: findings form the 2004 Crime and Justice Survey. Home Office Findings No. 245.

24. Hoffman, M. L. (1987). The contribution of empathy to justice and moral judgment. In N. Eisenberg \& J. Strayer (Eds.), Cambridge studies in social and emotional development. Empathy and its development (p. 47-80).

25. Izard CE, Fantauzzo CA, Castle JM, Haynes OM, Rayias MF, Putnam PH. (1995) The ontogeny and significance of infants' facial expressions in first nine months of life. Developmental Psychology; 31: 997-1013

26. Kring AM, Gordon AH. (1998) Sex differences in emotion: expression, experience, and physiology. J Pers Soc Psychol; 74: 686-703.

27. Marsh, Abigail \& Blair, Robert. (2008). Marsh AA, RJR Blair. Deficits in facial affect recognition among antisocial populations: a meta-analysis. Neurosci Biobehav Rev 32: 454-465. Neuroscience and biobehavioral reviews. 32. 454-65. 10.1016/j. neubiorev.2007.08.003.

28. Martin E. (2003). Oxford Dictionary of Law (7 ed.). Oxford: Oxford University Press.

29. Matthews, G., \& Wells, A. (1999). The cognitive science of attention and emotion. In T. Dalgleish \& M. J. Power (Eds.), Handbook of cognition and emotion (p. 171-192).

30. McAlister RW, Harkness EM, Nicoll JJ. (1998). An ultrasound investigation of the lip levator musculature. Eur J Orthod; 20: 713-20.

31. McClure EB. (2000). A meta-analytic review of sex differences in facial expression processing and their development in infants, children, and adolescents. Psychol Bull; 126: 424-53.

32. Mineka, S., \& Cook, M. (1993). Mechanisms involved in the observational conditioning of fear. Journal of Experimental Psychology: General, 122(1), 23-38.

33. Moore, J (2011) "Behaviorism," The Psychological Record: Vol. 61: Iss. 3, Article 9

34. National Bureau of Statistics (2016). Crime Statistics: Reported offence by Type and States, www.nigeriastat.gov.ng

35. Obi-Nwosu, Balageul and Nwafor (2018). Assessment of psychological and socio-economic Wellbeing of people living in black fly and other vector infested areas of Cameroon. Zik Journal Multidisciplinary Research 2; 1-19. 
36. Oguntunde, P. E., Ojo, O. O., Okagbue, H. I., \& Oguntunde, O. A. (2018). Analysis of selected crime data in Nigeria. Data in Brief, 19, 1242-1249.

37. Omotor D.G. (2010). Demographic and socioeconomic determinants and crimes in Nigeria (A panel data analysis). Journal of applied business and economics.

38. Posamentier MT, Abdi H (2003). Processing faces and facial expressions. Neuropsychol Rev. 13(3): 113-43.

39. Sariaslan Amir, Niklas Långström, Brian D'onofrio, Johan Hallqvist, Johan Franck, \& Paul Lichtenstein. (2013). "The impact of neighbourhood deprivation on adolescent violent criminality and substance misuse: a longitudinal, quasi-experimental study of the total Swedish population." International journal of epidemiology 42, no. 4: 1057-1066

40. Shinder D.L \& Cross M (2008). Scene of the Cybercrime. $2^{\text {nd }}$ Edition.

41. Skuse D (2003). Fear Recognition and the Neural Basis of Social Cognition. Volume 8, Issue2 pg. 50-60.

42. United Nations Office on Drug and Crime (2011). Global study on homicide. www.unodc.org

43. Webster, C., \& Kingston, S. (2014). Poverty and crime. London: Joseph Rowntree Foundation. 